\title{
SANEAMENTO BÁSICO E RAÇA
}

\section{BASIC SANITATION AND RACE}

\section{Fúlvia Rosemberg ${ }^{1}$ \\ Regina Pahim Pinto ${ }^{2}$}

ROSEMBERG, F, PINTO, R. P. Saneamento Básico e Raça. Rev. Bras. Cresc. Desenv. Hum., São Paulo, 5 (1/2), 1995.

Resumo: Com base num modelo interpretativo de segregação racial residencial, este artigo discute as diferenças de acesso de populações brancas e negras (pretos e pardos) a domicílios que usufruem de condições adequadas de saneamento segundo informações fornecidas por tabulações especiais da PNAD 87.

A análise dos dados centra-se em torno de dois eixos: condições de saneamento em que vivem crianças com menos de 7 anos e condições de saneamento em domicílios chefiados por brancos e negros (pretos e dardos).

Palavras-chave: segregação racial residencial, raça/cor; criança de 0 a 6 anos; saneamento básico.

Summary: This article discasses the difference in access to houses with adequate sanitary conditions when white and negro populations are considered, according to specific information tables from PNAD 87. An interpretativo model of residential race segregation is the basis for discussion.

The data analysis follows two directions: sanitary conditions for children under seven years old and for houses directed by whites and blacks.

Key-words: residential race segregation, race, children under seven years old, basic sanitation.

\section{INTRODUÇÃO}

Este artigo constitui parte de uma pesquisa mais ampla que se propõe a descrever e analisar, através de tabulações especiais de dados coletados pela PNAD 87 (Pesquisa Nacional por
Amostra de Domicílios), as condições de vida de crianças de 0 a 6 anos de idade à luz de seu pertencimento racial.

Descreveremos e discutiremos aqui as diferenças observadas entre as populações urbanas brancas e negras ${ }^{3}$ no acesso a domicílios que usu-

Trabalho realizado junto ao Departamento de Pesquisas Educacionais da Fundação Carlos Chagas. Cõntou com apõiõ dã FAPESP e dã Fundação Ford, este, no contexto do V Concurso de Dotações para Pesquisa sobre o Negro no Brasil, organizado pelo Centro de Estudos Afro-Asiáticos-CEAA.

1 Pesquisadora da Fundação Carlos Chagas e Professora Titular de Psicologia Social da PUC-SP. END.: Rua Monte Alegre 984 São Paulo-SP. CEP:05014-901 Fone: (011)263-0211 -Fax: (011) 815-1059.

2 Pesquisadora da Fundação Carlos Chagas. END.: Av. Professor Francisco Morato, 1565 - São Paulo - SP. CEP: 05513-900 Fone: (011) 813-4511 r. 236.

3 Denominamos população (ou raça) negra o conjunto de pessoas classificadas como pretas ou pardas no quesito cor que compõe o questionário da PNAD 87. 
fruem de condições adequadas de saneamento básico (água encanada e esgotamento sanitário). Comparar as condições de saneamento do domicílio em que vivem brancos e negros no contexto dessa pesquisa responde a três objetivos básicos: 1) contribuir no mapeamento de diferenciais raciais observados no Brasil, uma vez que, de acordo com levantamento bibliográfico realizado, as pesquisas sobre acesso ao saneamento básico não focalizaram até agora, a variável raça; 2) avançar na compreensão de variaveis que possam explicar taxas superiores de mortalidade infantil entre negros e que persistem mesmo quando se comparam populações brancas e negras provenientes de mesmo estrato econômico e educacional (TAMBURO 1987; 1991); 3) apontar a discriminação racial no acesso à qualidade domiciliar, indicador indireto da ocorrência de segregação racial no uso do solo urbano.

O texto é composto por quatro partes: uma breve descrição da política de saneamento básico instaurada no Brasil a partir dos anos 70 que, por não ter sido universalista, abre brechas para a persistência de discriminações econômicas e raciais no acesso a domicílios adequados; a explicitação de conceitos e variaveis que orientam a organização e análise dos dados coletados pela PNAD 87; a apresentação e análise dos dados, cuja interpretação sugere um padrão de segregação espacial dos segmentos raciais e, finalmente, um pequeno ensaio sobre segregação espacial e raça.

\section{POLÍTICAS DE SANEAMENTO BÁSICO}

As características atuais do saneamento básico no país refletem, em grande parte, decisões políticas e administrativas implantadas pelo governo militar (JORGE, 1987, JACOBI, 1989). Até 1970, os serviços de fornecimento de água e de esgotamento sanitário eram parcamente oferecidos à população pelas administrações municipais, que cobravam tarifas abaixo do custo real ${ }^{4}$.

O PLANASA - Plano Nacional de Saneamento, elaborado em 1971, alterou profundamente estas condições. Visando a extensão da cobertura, apoiou-se nos dois princípios gerais que mar- caram as políticas sociais do período: a centralização das decisões e a auto-sustentação financeira do serviço público (JACOBI, 1989, p. 23).

De acordo com a argumentação do governo federal na época, a retirada da atribuição municipal na construção e no abastecimento de redes de água e de esgoto dificultaria a pressão local contrária a uma tarifação realista, condição indispensável para a auto-sustentação do serviço. Foram, então, criadas Companhias Estaduais de Saneamento (CES) que atuaram em acordo com o princípio estabelecido pelo PLANASA: auto-sustentação na tarifação, minimizando a aplicação de recursos a fundo-perdido por parte do poder público (JACOBI, 1989, p. 26).

Os investimentos e a expansão das redes de água e esgoto que se observaram no país no período 70-84, repetiram de um modo quase constante, esta lógica da racionalidade empresarial, apenas mitigada em momentos eleitorais, quando o saneamento básico, como outras benfeitorias de infra-estrutura, foram usados para seduzir eleitores e eleitoras ${ }^{5}$.

Assim, o PLANASA atribuiu prioridade ao abastecimento de água, em detrimento do esgotamento sanitário, pelo fato de os investimentos per capita nesta área representarem a metade dos necessários aos sistemas de esgoto sanitário, privilegiando aqueles projetos que aportassem maiores recursos a curto prazo (JACOBI, 1989). "Considerando-se o período de 1968 a 1984, os investimentos em sistemas de abastecimento de água significaram uma média global de $72 \%$ dos investimentos globais do PLANASA, no período"6 (JORGE, 1987, p. 177). O investimento refletiu-se diretamente na cobertura do atendimento: $76,2 \%$ dos moradores em domicílios permanentes eram servidos por sistema de água ligado à rede geral e apenas 39,0\% pela rede geral de esgoto, em 1984 (Fonte: PNAD 84, apud FARRET, 1988, p. 231).

A racionalidade empresarial também determinou que o PLANASA investisse preferencialmente na região Sudeste, em especial no Estado de São Paulo, que recebeu a fatia do leão. Em decorrência, as populações residentes no Sudeste e no Estado de São Paulo são as que dis-

4 Em 1970, apenas 64\% da população era atendida por rede pública de abastecimento de água e apenas 21\% das populações urbanas residiam em moradias com coleta de esgoto.

5 Tentando captar o impacto da crise econômica de 1982 nos investimentos federais em saneamento básico. FARTEI (1988, p 227) evidencia uma "protelação dos cortes nos investimentos na arca devido às eleições estaduais e municipais de 1982 (e. também. com vistas às nacionais de 1984 e 1985), eventos que, historicamente estão atrelados a programas na área do desenvolvimento urbano".

6 No período de 69-84. o PLANASA investiu 60,9\% de seus recursos na região Sudeste. O Estado de São Paulo recebeu 42,6\% dos recursos, seguido de longe de Minas Gerais (10\%) e Bahia (9,5\%). Considerando-se exclusivamente o investimento em esgoto observa-se o pnvilegiamento do Sudste e do Estado de São Paulo, que receberam, respectivamentc, 75,6\% e 63,7\% dos recursos. 
põem de melhores condições de saneamento básico (Tabelas 1 e 2).

Finalmente, como se trata de recursos escassos e que são investidos dentro do jogo de mercado, tem-se observado uma forte relação positiva entre nível de renda e acesso ao saneamento (FARRET, 1988, p. 222). Esta desigualdade social não constitui apenas mais uma das conseqüências da lógica perversa de o investimento público brasileiro ser tanto menor quanto mais pobre for a população, mas também do impacto no valor do solo urbano decorrente do fornecimento de infra-estrutura urbana que gera, por sua vez, um emperramento das populações pobres para solos urbanos mais baratos? ${ }^{7}$. VETTER e SIMÕES (1980), ao analisarem este processo, falam em "segregação residencial segundo grupos de rendimento familiar". Neste artigo, apoiadas em um modelo interpretativo equivalente, falaremos em "segregacão residencial (ou espacial) segundo os segmentos raciais”. É importante salientar, porém, que estamos falando em segregação residencial ou espacial no contexto brasileiro, portanto, numa acepção diferente da utilizada para expressar a segregação racial residencial tal como ocorre em países que conhecem/conheceram a experiência de guetos raciais ou do apartheid. Como nos alerta TELLES (1991, p. 343), os padrões brasileiros de segregação racial residencial devem ser entendidos tendo-se em mente as seguintes características: "a desvantagem territorial dos não brancos, num país de desenvolvimento muito desigual, um continuum de cor, ao invés de uma linha divisória de cor; a não utilização do sistema legal nas questões raciais; a ideologia racial dominante; e a relativa ausência de instituições paralelas para os negros”.

\section{CONCEITOS E VARIAVEIS}

\section{Conceitos}

No estudo sobre acesso ao saneamento básico e mortalidade, VETTER e SIMÕES (1980) assinalaram que "existe sempre um grau relativamente alto de arbitrariedade na definição operacional de 'adequação' das instalações de água e esgoto quando nos servimos dos conceitos de um censo" (p. 8). Com efeito, a adequação depende de um conjunto de fatores, tais como a densidade populacional, as características do solo, e as qualidades do sistema. "Por exemplo, uma fossa séptica poderia ser uma instalação adequada de esgoto, se a densidade populacional permitisse uma separação entre ela e um poço razoavelmente profundo (...) e quando as condições de solo permitissem ser absorvido o esgoto do domicílio" (VETTER e SIMÕES, 1980, p. 8). Esta interdependência entre tipo de fornecimento de água e esgotamento sanitário tem sido assinalada por especialistas (JORGE, 1987) como uma das inadequações da política implantada pelo PLANASA: o aumento do consumo de água sem um investimento equivalente na rede de esgotos tende a agravar as condições de saneamento.

Tendo em vista este fato, Vetter e Simões conceituam adequação de saneamento do domicílio através da combinação entre o tipo de fornecimento de água e o de esgotamento sanitário, procedimento que também tem sido usado pelo IBGE (especialmente no Perfil estatístico de mães e crianças no Brasil) e por outros pesquisadores (ANDRADE, s.d.).

Seguindo o modelo adotado pelo IBGE, conceituamos como adequados os domicílios que dispunham da rede geral de esgoto ou fossa séptica e que estivessem ligados à rede geral de água com canalização interna (FIBGE/UNICEF, 1988, p. XV) ${ }^{8}$.

\section{Variáveis}

A política de saneamento básico implantada pelo PLANASA acarretou uma distribuição bastante desigual de domicílios adequados pelo território nacional gerando uma concentração em zona urbana: 95,5\% dos domicílios adequados no plano do saneamento básico situam-se em zona urbana (Fonte: Tabulações especiais da PNAD 87) e nas regiões Sudeste e Sul (Tabelas l e 2),

Por outro lado, como tem sido assinalado na bibliografia (TELLES, 1991), a distribuição dos segmentos raciais pelo território nacional também é bastante heterogênea, refletindo, ao mesmo tempo, a densidade populacional da região e a predominância de uma ou de outra subpopulação racial. Assim, apesar de pretos e pardos não constituírem a maioria da população que reside na região Sudeste, é aí que encontramos, comparativamente ao território nacional, a maior con-

7 Por exemplo, em Belo Horizonte, o aumento do preço da terra com infra-estrutura foi de $40 \%$ contra $26 \%$ quando não ocorriam estas melhorias (PLAMBEL 1978 apud FARRET, 1988, p, 224).

8 A conceituação que usamos é uma transposição da definição de "domicílio inadequado" para "domucílio adequado": "considerou-se como de água com canalização interna” inadequados os domicílios que não dispunham de rede geral de esgoto ou fossa séptica e/ou rede geral (FIBGE/UNICEF. 1988, p. XV). 
centração de pretos e a segunda maior concentração de pardos após o Nordeste (Tabela 3).

Portanto, na região Sudeste se encontra, simultaneamente, a maior concentração de domicílios adequados $(67,3 \%)$ e de moradores brancos e pretos, diferentemente do que ocorre na região Nordeste onde se encontram apenas $10,1 \%$ dos domicílios brasileiros adequados e uma grande concentração de declarantes pardos (Tabelas 1 e 3).

Diante de tais disparidades regionais e do nosso intuito em captar o diferencial racial no acesso a condições adequadas de saneamento, pareceunos sensato tomarmos algumas decisões quanto à análise das variáveis, explicitadas a seguir:

1. centrar a análise exclusivarnente em domicílios situados em região urbana onde a cobertura, não sendo nem universal nem extremamente exígua, dá maior visibilidade a processos seletivos;

2. comparar as subpopulações raciais dentro de cada macro-região a fim de controlar o impacto de sua distribuição desigual pelo país bem como da diversidade de distribuição de domicílios adequados no plano do saneamento pelo território nacional.

Também, de acordo com achados relativamente constantes na bibliografia contemporânea sobre desigualdades raciais no Brasil que se apóia em informações macro censitárias (cf. particularmente textos contidos em LOVELL, 1991), os dados foram analisados, sempre que possível, controlando-se as variáveis rendimento mensal domiciliar per capita e sexo do chefe de domicílio.

\section{RESULTADOS}

Os resultados serão apresentados em torno de dois eixos: condições de saneamento em que vivem crianças brancas e negras (pretas e pardas), com menos de 7 anos de idade; condições de saneamento em domicílios chefiados por brancos e negros (pretos e pardos). Estes eixos foram escolhidos não apenas por facilitarem a análise nesta fase dos trabalhos sobre o tema, mas também pelos significados que se pode atribuir ao saneamento na compreensão das desigualdades raciais no Brasil.

Na análise da adequação sanitária das residências de crianças com menos de 7 anos de idade, o saneamento básico pode ser focalizado enquanto uma das variáveis explicativas das diferenças nos indices de mortalidade infantil entre os segmentos raciais, como Estela Tamburo tem assinalado (TAMBURO, 1987, 1991). Na análise das condições dos domicílios chefiados por brancos, pretos e pardos, o saneamento básico pode vir a ser interpretado como um dos indicadores de segregação residencial dos segmentos raciais.

\section{Crianças}

Lembramos que, no Brasil, a PNAD 87 estimou a presença de 23,7 milhões de crianças de 0 a 6 anos vivendo em domicílios particulares, $69,2 \%$ das quais residindo em zona urbana. Deste contingente de crianças de 0 a 6 anos residindo nas áreas urbanas, 59,4\% foram declaradas brancas, $4,5 \%$ pretas, e $35,6 \%$ pardas $^{9}$.

Dentre as 16,4 milhões de crianças com menos de 7 anos residindo em zona urbana, um pouco mais da metade $(53,7 \%)$ vive em domicílios adequados no plano do saneamento, porcentagem inferior àquela dos domicílios com saneamento básico adequado (63,5\%). Esta desvantagem pode ser explicada pelo fato de que as crianças com menos de 7 anos constituem o segmento etário onde se encontra a maior concentração de pobreza no Brasil (CAMPOS et al., 1993).

Ciclo de vida da família e precariedade de creches/pré-escolas são explicações que temos aventado para esta constatação: famílias jovens (portanto com menor ingresso) tem filhos pequenos em idade próxima (portanto não contam com filhos maiores para trabalhar), que necessitam do cuidado de um adulto, geralmente a mãe, que não pode trabalhar fora pela falta de creches/pré-escolas públicas e pela falta de dinheiro para o pagamento de uma solução particular (babá, vizinha, creche/pré-escola privada).

Além do reduzido número de crianças pequenas que usufruem de condições adequadas de saneamento em seus domicílios, é necessário lembrar que, salvo algumas raras que frequentam creches/pré-escolas em boas condições, estas crianças, diferentemente de boa parte de adultos, de crianças maiores e adolescentes, só convivem no espaço da casa, não tendo alternativas de outros locais (trabalho e escola) em que possam dispor de melhores condições de saneamento. Assim, a criança pequena tende a se servir, nas 24 horas do dia, de água e de esgotamento inadequados, o que potencializa o impacto de viverem em moradias inadequadas no plano do saneamento.

Os dados contidos na Tabela 4 reforçam, de inicio, o que a literatura tem apontado (JORGE, 1987 e FARRET, 1988): a adequação do do-

9 Os restantes 0,5\% referem-se a crianças declaradas amarelas que foram excluídas desse estudo. 
micílio está diretamente associada ao nível de rendimento (neste estudo, rendimento domiciliar) e varia intensamente de uma região fisiográfica para outra. A população infantil que usufrui de melhores condições de saneamento reside na região Sudeste; as piores condições se encontram nas regiões Nordeste e Centro-Oeste.

A variação regional é tão intensa que o índice de adequação do domicílio de crianças situadas no nível de rendimento mensal domiciliar per capita até $1 / 4$ S.M. no sudeste $(34,8 \%)$ equivale, no Centro-Oeste, ao índice de adequação dos domicílios de crianças com rendimento mensal domiciliar per capita entre 1 e 2 S.M. (36,7\%). Também, dentro de uma mesma região, os índices de adequação podem variar intensamente de acordo com o nível de rendimento domiciliar, variação mais intensa nas regiões Norte, Nordeste e Centro-Oeste. Nestas regiões, apenas aproximadamente $8 \%$ das crianças residindo em domicílios pobres (até 1/4 S.M.) usufruem de adequadas condições de saneamento. Esta situação é particularmente grave na região Nordeste onde, como se sabe, o número de crianças nesta faixa etária e neste nivel de rendimento é bastante significativo: de acordo com estimativas da PNAD 87, 1,0 milhão de crianças com menos de 7 anos viveriam em domicílios com rendimento mensal domiciliar até $1 / 4$ de S.M. sendo que apenas 90,6 mil usufruiriam de saneamento adequado.

A Tabela 4 evidencia, também, um diferencial racial importante no acesso das crianças a domicílios em condições adequadas de saneamento. Considerando-se o conjunto das crianças brasileiras com menos de 7 anos residindo em áreas urbanas, $64,8 \%$ daquelas declaradas brancas vivem em domicílios adequados, porcentagem que cai para $37,1 \%$ quando se trata da subpopulação negra (pretos e Pardos).

O diferencial racial é persistente no interior de cada nível de rendimento e de cada região, notando-se, apenas, duas exceções na faixa de rendimento mais de $1 / 4$ a $1 / 2$ S.M. mensal domiciliar per capita nas regiões Nordeste e CentroOeste. As diferenças entre brancos e negros são mais intensas na região Sudeste.

Comparando-se, agora, as subpopulações preta e parda entre si, observa-se que nem sem- pre as crianças pretas vivem em piores condições de saneamento que as pardas (Tabela 5) assim, em todas as regiões, pelo menos em um nível de rendimento, a subpopulação preta evidencia índices melhores de saneamento básico. Além de estarmos lidando, muitas vezes, com contingentes muito pequenos de população infantil preta ${ }^{10}$ (o que diminui a confiabilidade dos dados), a distribuição de pretos pelos estados que compõem as macro-regiões varia muito. Não se pode, porém descartar a hipótese de que crianças pretas vivendo em domicílios inadequados desapareçam das estatísticas por morte precoce. Com efeitc como evidenciou a pesquisa de TAMBUR (1991), a taxa de mortalidade infantil entre crianças pretas é superior à de brancas e pardas. Assim, a morte precoce mais intensa nesse segmento populacional poderia eliminar das estatísticas crianças pretas que, se continuassem vivas, aumentariam o contigente daquelas residindo em domiíilios inadequados $^{11}$.

\section{Domicílios}

A PNAD 87 estimou a existência de 32,1 milhões de domicílios particulares permanentes para o conjunto do território nacional, dos quais 24,3 milhões estão situados em região urbana (75,8\%), sendo que destes, $63,5 \%$ foram considerados adequados no plano de saneamento básico. Em acordo com achados anteriores (JORGE 1987), também em 1987 as condições de adequação dos domicílios estão associados à sua inser ção regional e ao nível de rendimento domiciliar.

Diferentemente, porém, do acesso a outros bens e serviços (como rendimento e educação) - onde se evidenciam piores condições de vida nos domicílios chefiados por mulheres (BARROSO, 1978) - não se observa uma associação entre adequação do domicilio e sexo do chefe no sentido habitual. Isto é, no plano do saneamento básico nem sempre os domicílios chefiados por mulheres apresentam índices de adequação inferiores aos dos domicílios chefiados por homens. Dentre as explicações para este dado - que já havia sido apontado em outro estudo (ANDRADE, s.d.) ${ }^{12}$ - é possível destacar a idade do chefe (as mulheres chefes são mais velhas que os homens chefes), as diferenças quan-

10 Vários níveis de rendimento em várias regiões dispõem de um contingente estimado de crianças em torno de 3 mil casos, na região Norte trabalhamos com efetivos estimados ainda menores, abaixo do milhar.

11 Alguns pesquisadores evidenciaram o ritmo menos acelerado de crescimento da população preta (BERQUÓ et al., 1986) que apresentou, inclusive, um decréscimo no periodo 1940-1950. Em estudo recente, ROSEMBERG: PIZA (1994) evidenciam que a diminuição de pretos na população ocorreu fundamentalmente, entre os analfabetos, população mais pobre e que, hipoteticamente estaria vivendo em domicílios inadequados no plano de saneamento.

12 Este autor analisou exclusivamente chefias de domicílios unifamiliares, que perfazem aproximadamente 30 milhões dos 32,1 milhões de domicílios. 
to às prioridades na escolha de um domicílio quando chefiado por mulher ou por homem e a mobilização de grupos de mulheres por melhores condições de infra-estrutura urbana.

Além destes componentes já referidos na literatura, os dados da PNAD 87 evidenciam, também, um diferencial racial persistente no acesso a domicílios com adequadas condições de saneamento. Assim, nos domicílios chefiados por brancos foram encontrados melhores índices de saneamento que naqueles chefiados por negros, de forma persistente e independentemente de sua localização regional, do nível de rendimento domiciliar e do sexo do chefe de domicílio (Tabelas 6 e 7).

A Tabela 6 aponta: um aumento progressivo das condições de adequação à medida que aumenta o nível de rendimento domiciliar em ambos segmentos raciais (brancos e negros) e em todas as regiões; uma grande variação regional, destacando-se a região Centro-Oeste como a de pior condição para ambos os segmentos raciais em todos os níveis de rendimento e a região Sudeste como a de melhor condição; um efeito cumulativo das variáveis rendimento domiciliar, inserção regional e pertencimento racial, de tal forma que o melhor índice de saneamento entre negros residindo no Centro-Oeste praticamente equivale ao pior índice de saneamento entre brancos residindo no Sudeste; um nítido diferencial racial que resiste ao controle de variáveis como a localização regional e as diferenças de rendimento, sendo mais intenso nas regiões com melhores índices de saneamento (Sudeste, Sul e Norte).

A comparação entre chefia masculina e feminina sugere uma tendência - mas não uma constância - à maior incidência de adequação nos domicílios chefiados por mulheres em ambos os segmentos raciais e para todos os níveis de rendimento. Notam-se algumas exceções regionais, esta tendência mas que não configuram uma dis tribuição sistemática (Tabela 7).

Observa-se, portanto, uma associação estreita entre adequação do domicílio e pertenci mento racial do chefe, além daquelas já evidenciadas como por exemplo nível de rendimento e inserção regional.

Resta-nos, ainda, comparar dentro do segmento negro como se situam as subpopulaçõe de chefes de domicílio pretos e pardos (Tabela 8).

Diferentemente do que tem sido observado para outros indicadores sociais, nem sempre no interior do segmento negro a subpopulação dos chefes de domicílio que se declaram pardo apresenta melhores índices de adequação que a subpopulação preta. Os domicílios com chefia preta obtiveram índices de adequação superiores aos dos pardos na maioria dos níveis de rendimento nas regiões Sul e Centro-Oeste.

Fazendo-se interferir, também, a variáveis sexo do chefe (Tabela 9), o padrão da distribuição torna-se bastante complexo, distanciando-se, em muito, da sequência hierárquica de benefícios sociais habitualmente encontrada em outros indicadores sociais: chefes homens pardos, chefes homens pretos, chefes mulheres pardas, chefes mulheres pretas.

Como se observa, a despeito de persistirem interrogações na compreensão de algumas configurações dos dados, constata-se um nítido diferencial racial no acesso a condições adequadas de saneamento. A constatação de desigualdades raciais no acesso ao saneamento básico público sugere que a segregação residencial, muitas vezes provocada pela própria melhoria da infraestrutura urbana (VETTER e MASSENA, 1982), nãc se origina apenas nas diferenças de rendimento das famílias mas interage com sua origem racial. É possível que o valor do solo urbano seja também determinado pela concentração de residentes brancos e negros.

De qualquer forma, o diferencial racial no acesso ao saneamento básico adequado sugere simultaneamente, uma concentração diferenciado em solo urbano de domicílios chefiados por brancos e por negros.

Neste sentido o modelo interpretativo da segregação residencial racial parece-nos bastante profícuo para explicar as desigualdades observadas. Esta questão poderá ser melhor compreendida na medida em que se conseguir explicitar, mais plenamente, a dinâmica da concentração diferencial dos segmentos raciais no país e os fatores que concorreram ou vêm concorrendo para a sua configuração, tema que trataremos a seguir.

\section{SECREGAÇÃO ESPACIAL E RAÇA}

Ultimamente, estudos sobre relações raciais no Brasil, vêm apontando a concentração espacial da população negra em determinadas regiões ou micro regiões e, conseqüentemente, a sua segregação em relação ao grupo branco, como um dos aspectos a serem considerados na compreensão das desigualdades raciais (HASENBALG, 1979; ROLNIK, 1989; TELLES, 1991).

Esse fenômeno tem raízes históricas e, inicialmente, pode ser explicado em função do uso de mão-de-obra escrava. O estudo de HASENBALG (1979) mostra como os sucessivos ciclos econômicos regionais (açúcar, mineração, algodão e café) constituíram a força motriz do tráfico de escravos africanos e o determinante da locali- 
zação espaço-temporal da população escrava, durante o período colonial e o Império.

À medida que essas atividades econômicas adquiriam dinamismo, aumentava o contigente populacional negro nas regiões onde elas se desenvolviam, em virtude da intensificação do tráfico e, também, do deslocamento de mão-de-obra escrava das regiões que entravam em declínio econômico. Por sua vez, os mestiços ${ }^{13}$ e pretos livres tenderam a permanecer concentrados nas regiões que entravam em estagnação - regiões agrícolas no Nordeste onde se desenvolvera a cultura da canade-açúcar e a região de mineração em Minas - dedicando-se à economia de subsistência, sofrendo grande deterioração econômica.

Já na região Sudeste, o trabalho escravo foi introduzido tardiamente para atender à de manda da lavoura cafeeira que iniciou o seu desenvolvimento no segundo quartel do século XIX, o que não so resultou numa proporção inferior de africanos, como também limitou o desen volvimento da miscigenação racial e a formação de uma população de cor livre na região.

Assim, por ocasião da Abolição, a grande maioria da população negra se concentrava fora da região onde estava se formando uma sociedade urbana e industrial.

Esse padrão de distribuição espacial praticamente se manteve inalterado. Reportando-se aos dados de 1950, HASENBALG (1979) mostra que ocorreu um leve aumento da população não bran$\mathrm{Ca}^{14}$ no Brasil subdesenvolvido e um aumento maior da população branca na região Sudeste. Para isso contribuiu não somente todo este deslocamento tardio da população negra para esta região, como também a opção por uma política de migração européia destinada a suprir a necessidade de mão-de-obra na região Sudeste.

Se esta configuração ocorreu em nível macro através da concentração da população negra em determinadas regiões, também em nível micro, como mostram os estudos de ROLNIK (1988, 1989), formaram-se espaços brancos e negros tanto no meio rural, com a casa grande e a senzala, como no meio urbano.

Em configurações urbanas como São Paulo e Rio de Janeiro, cidades em que essa autora estudou a formação de territórios negros reeditouse esse modelo de segregação, seja nas chácaras, seja nos sobrados, onde as dependências reservadas aos escravos localizavam-se fora dp edificio principal.
Nesses centros ainda constituíram-se vários outros territórios negros: as irmandades, que organizavam fundos para a compra de alforrias, os mercados, locais por onde circulavam obrigatoriamente escravos de ganho ou libertos, os pais de santo que ali se abasteciam nos ervanários africanos e cuidavam da saúde fisica e mental dos escravos; os quilombos paulistanos que se desenvolveram no final da escravidão em São Paulo; as casas de cômodos e porões, única opção de moradia barata para os negros libertos; e, mesmo, certas aldeias na periferia das cidades.

Esse panorama iria alterar-se com a extinção do tráfico, a Abolição e a introdução da mão-de-obra estrangeira. A cidade de São Paulo, por exemplo, italianizou-se. Embora as razões fossem sobretudo econômicas, a opção pelo braço livre europeu significou também "usar mãode-obra 'civilizada', já que não era possível romper repentinamente com todo o arcabouço ético-político da escravidão, montado através da identificação 'selvagem-inumano-cativo'. Pelo contrário, 'barbárie versus civilização', continuou sendo a pedra de toque do discurso da classe dominante na Primeira República (1989-1930) para justificar seu exercício cotidiano de poder.” (ROLNIK, 1988a, p. 77, aspas no original).

A argumentação que subsidiou esta opção passou então a se constituir no critério fundamental para definir quem podia constituir o pacto de igualdade entre os homens na ordem liberal republicana e quem estava fora dele. Ou seja, é através deste argumento que se justificaram ações repressivas contra determinados indivíduos ou grupos sociais. Abrir as portas para a pobreza européia, e Ihe dar o lugar de assalariado, implicou em diferenciar internamente a pobreza, produzindo ao mesmo tempo a figura do marginal. Nesse processo, bem como na definição dos lugares que cada grupo ocuparia na hierarquia do espaço social a estigmatização racial teve um papel importante. Isso fica evidente quando se examina o processo de redefinição dos lugares da cidade (ROLNIK, 1988a, p. 77, aspas no original).

O contingente negro, por exemplo, experimentaria um agudo processo de marginalização não só devido à preterição de sua mão-de-obra em favor da mão-de-obra imigrante e a conseqüente redefinição da noção de trabalho, como também devido a seu deslocamento dos espaços que ocupava em consequência da remodelação da cidade.

13 Neste contexto, o autor usa a palavra mestiço como sinônimo de pardo.

14 População não branca está sendo utilizada como sinônimo de negros (pretos e pardos). 
Nessa nova configuração, a presença africana vai se tornando cada vez mais marginal, mais estranha. Já em 1886 é promulgado o Código de Posturas, onde se expressa claramente a intenção de proibir as práticas africanas nos territórios negros - saída das quitandeiras porque atrapalham o trânsito, transferência dos mercados para a periferia porque conspurcam a cidade, proibição das atividades dos pais de santo, classificados como embusteiros.

No que diz respeito à classe dominante, $\mathrm{o}$ projeto de cidade européia também acarretou transformações, como a troca dos sobrados do centro por bairros projetados - Campos Elísios, Vila Buarque, Higienópolis e, finalmente, avenida Paulista - deslocamento este que, por sua vez, acabou definindo novos territórios negros.

ROLNIK (1988b) mostra o processo de transformação de regiões como o Bexiga e a Barra Funda com a proliferação das casas de cômodos e habitações coletivas e a sua consolidação ou transformação em territórios negros, pela facilidade dos seus moradores encontrarem colocação no setor de serviços nesses bairros que então se formavam.

Neste período, qualquer um destes quilombos tinha a fama de desclassificado, marginal, desorganizado, devido a sua não proletarização, com a conseqüente ocasionalidade da distribuição do tempo de lazer e de trabalho, e o próprio tipo de vida que se desenvolvia nas habitações coletivas que aí prenominavam: intensidade de uma vida em grupo não familiar, densidade dos contatos no dia a dia, bem como um conjunto de gostos, um jeito de corpo que, embora para a comunidade negra fosse o elemento que liga e sustenta um código coletivo que institui a comunidade, para a classe dominante branca e cristã desafiava os padrões morais.

Uma nova redefinição dos territórios negros em São Paulo ocorreu com a entrada do "negro" e do "mulato" 15 no mercado formal de trabalho, em virtude da abertura de oportunidades de trabalho. À medida que esse processo se desenvolvia, intensificava-se a luta para desmarginalizar o negro, inclusive em termos territoriais, por parte daqueles que já estavam integrados. Lideranças negras da época, principalmente aquelas ligadas à Frente Negra (fundada em 1931), desenvolveram intensa campanha para tirar os negros dos porões e cortiços, incentivando-os a comprarem terrenos e a construírem suas próprias casas. Como resultado dessa campanha, muitos negros adquiriram terrenos em loteamentos situados em bairros afastados, ocorrendo então a dispersão dessa população pela periferia onde não se formaram, entretanto, territórios negros tão caracterizados como o Bexiga ou a Barra Funda.

Processo mais ou menos semelhante ocorreu no Rio de Janeiro que, como São Paulo, por ocasião da Abolição também embranqueceu, embora em menor grau, pois essa região, por ter recebido um menor contingente de imigrantes europeus, além de uma migração maciça de libertos da zona rural para a zona urbana, continuou sendo a area de maior concentração de negros da região Sudeste.

A reforma urbana e a operação limpeza que ai ocorreram se deram de forma drástica, atingindo em cheio os mais importantes quilombos da cidade, a região portuária da Saúde e Gamboa e os cortiços e habitações coletivas da cidade nova. Como conseqüência, a população negra, deslocou-se para os morros e os territórios suburbanos que acompanhavam as linhas de trem, configurando-se novos temtórios negros

A partir de 1940, a tendência ao embranquecimento destas duas cidades começou a se reverter. De fato, dados dos censos de 1940, 50 e 80 apontam para o aumento da participação do não brancos na sua população, consequência das migrações internas principalmente de mineiros nordestinos (ROLNIK, 1989)

Outros estudos, utilizando-se de dado mais recentes, também sugerem um padrão de segregação espacial racial no Brasil. TELLES (1991), com base no censo de 80, mostra que distribuição de brancos, pardos e pretos pelo território brasileiro é muito desigual do ponto de vista regional. Os brancos concentram-se na áreas mais desenvolvidas (São Paulo e estados do Sul), os pardos nas menos desenvolvidas (Nordeste) e os pretos, nas áreas intermediárias embora com uma distribuição mais semelhante dos pardos do que à dos brancos. ${ }^{16}$

A composição racial das áreas urbanas também se diferencia. Nas áreas urbanizadas da região Norte e Nordeste a população é majoritariamente não branca o que não ocorre nas áreas urbanizadas das demais regiões, onde os não brancos, com apenas duas exceções (Belo Horizonte e Campo Grande), constituem minoria;

Esmiuçando ainda mais os dados dentro das áreas urbanas, através dos índices de desse-

15 Terminologia usada por ROLNIK (1988b) para significar pretos e pardos.

$16 \mathrm{O}$ autor usa o termo negro para designar os pretos. 
melhança e de interação ${ }^{17}$, Telles mostra outra particularidades da distribuição racial brasileira Assim, há uma variação substancial na dessemeIhança residencial das 40 maiores áreas urbanas brasileiras. Em 35 delas, a segregação preto branco medida por dessemelhança é maior do que a segregação pardo-branco, sendo que as 5 áreas em que isto não ocorre locaiizam-se na região $\mathrm{Su}$ deste, principalmente no Estado de Minas Gerais. Do ponto de vista regional a segregação pretobranco medida por dessemelhança é mais elevada no Norte, já a segregação pardo-branco mais elevada no Sul.

Por sua vez, o contato inter-racial residencial, medido pelos índices de interação ${ }^{18}$, registra níveis surpreendentemente baixos em algumas regiões do Brasil, conseqüência da concentração territorial desigual de brancos e não brancos.

Essa reconstrução, ainda que parcial e bastante simplificada, desse processo de deslocamento e alceamento dos segmentos raciais pelo território nacional, dos acontecimentos subjacentes a essa dinâmica, bem como de algumas reflexões sobre as características da segregacão, mostram que o modelo de segregação racial deve ser aprofundado no sentido de se detectar os diferentes níveis de segregação racial como também ser complementado por outros estudos. Estamos falando aqui, não só de estudos que

\section{BIBLIOGRAFIA}

ANDRADE, T. A. As condições de saneamento dos domicílios chefiados por mulheres $\mathrm{s}$. d.[mimeo].

BARROSO, C. Sozinhas ou mal acompanhadas; a situação das mulheres chefes de família. In: Seminário: A Mulher na Força de Trabalho na América Latina. Rio de Janeiro, 1978.

BERQUO, E.; BERCOVICH, A. M.; GARCIA, E. M. Estudo da dinâmica demográfica da população negra no Brasil. Campinas, NEPO/ UNICAMP, 1986. (Textos NEPO, 9). detectem de modo mais amplo os fatores, sejam de natureza econômica e política que, nos dias de hoje, continuam a agir no sentido de manter ou agudizar essa configuração como de estudos que os complementem, na medida em que sejam capazes de apreender no nível micro como se dá a dinâmica que leva a essa configuração. Nesse sentido, certamente terão de levar em conta o preconceito racial que, como vimos, não só contribui para manter essa configuração como também desencadeia processos que resultam nessa configuração diferencial.

Apenas à guisa de conclusão, gostaríamos de lembrar aqui o estudo de DIAS (1979 apud HASENBALG, 1987) sobre o aproveitamento diferencial de alunos de diversas camadas sociais, em escolas do Rio de Janeiro, que mostra como a residência numa mesma área geográfica não garante o acesso igualitário dos diferentes segmentos sociais aos equipamentos aí disponíveis. Alunos pobres e, inclusive, alunos negros tendem a ser recrutados para escolas de alunado mais pobre, onde em geral reina um pessimismo à respeito das suas potencialidades e que acaba se refletindo negativamente no seu desempenho. Desvendar os meandros desse mecanismo que acaba segregando os segmentos raciais é um dos desafios com que se depara o estudioso das relações raciais no nosso país.

CAMPOS, M. M.; ROSEMBERG, F.; FERREIRA, I. M. Creches e pré-escolas no Brasil. São Paulo, Cortez/Fundação Carlos Chagas, 1993.

FARRET, R. L. A crise econômica e os investimentos federais em desenvolvimento. In: CHAHAD, J. P. Z.; CERVINI, R. orgs. Crise e infância no Brasil. O impacto das políticas de ajustamento econômico. São Paulo, IPE/ USP, 1988, p.221 239.

FIBGE. Pesquisa nacional por amostra de domicílios - 1987. Rio de Janeiro, FIBGE/ UNICEF,1990. v.1.

17 Estes índices referem-se a duas dimensões distintas da segregação residencial. O índice de dessemelbança mede o grau de igualdade e relação ao qual brancos e não brancos se distribuem pela paisagem urbama. Ele varia de 0 a , sendo que um índice de dessemelhança entre 0,1 e 0,3 mdica leve segregação residencial; entre 0,4 e 0,6, segregação moderada e entre 0,7 e 1,0, alto nível de segregação. $O$ índice de interação fornece a probabilidade de que pessoas de um mesmo grupo racial estejam em contato com pessoas de outro grupo racial, por residirem na mesma árca censitária. É um índice, portanto, que tem alta correlação com a composição racial da área urbana. Assim, no Brasil, dado o grande contigente de não brancos em algumas cidades. é possível encontrarem-se níveis relativamente baixos c segregação, se medida por dessemelhamça, Juntamente com altos níveis de segregação, se medida por interação.

18 Neste estudo, Telles selecionou cinco índices de interação. O índice de isolamento, que mostra a probabilidade de que os brancos venham a compartilhar da mesma área censitária com outros brancos. Os quatro índices restantes medem a probabilidade de interação branco X preto. branco X pardo; preto X branco e pardo X branco. 
Perfil estatistíco de crianças e mães no Brasil: sistema de acompanhamento da situação sócio-econômica de crianças e adolescentes 1981. 1983. 1986. Rio de Janeiro: IBGE, Departamento de Estatística e Indicadores Sociais, 1988.

HASENBALG, C. A. Desigualdades sociais oportunidade educacional. A produção do fracasso. Cad. Pesq.. São Paulo. 63:24-6 1987.

Discriminações e desigualdades raciais no Brasil. Rio de Janeiro, Graal, 1979.

JACOBI, P. Movimentos sociais e políticas públicas: demandas por saneamento básico e saúde. São Paulo 1974-84. São Paulo, Cortez, 1989.

JORGE, W. E. A política nacional de saneamento. pós - 64. São Paulo, 1987. [Tese de Doutorado - Faculdade de Arquitetura e Urbanismo da USP]

LEVISON, D. Child care in metropolitan Brazil. WorldBank, 1989.[mimeo].

LOVELL, P. A. org. Desigualdade racial no Brasil contemporâneo. Belo Horizonte, UFMG/ CEDEPLAR, 1991.

ROLNIK, R. Territórios negros nas cidades brasileiras (etnicidade e cidade em São Paulo e no Rio de Janeiro). Estudos Afro-Asiáticos, Rio de Janeiro, 17:29-41, 1989.

, São Paulo, inicio da industrialização: o espaço e a política. In: KOWARICK, L. org. . As lutas sociais e a cidade. Rio de laneiro, Paz e Terra, 1988a, p.75-92.
Territórios negros em Sao Paulo uma história. 1988b. [mimeo].

ROSEMBERG, F.; PIZA, E. Analfabetismo, raça e gênero nos censos brasileiros. In: Fundação Carlos Chagas/Pundação Ford. Adultos Analfabetos: gênero e raça. Relatório final. São Paulo, 1994.

TAMBURO, E. M. G. Desiguais perante a morte. In: LOVELL, P. A. org. Desigualdade racial no Brasil contemporâneo. Belo Horizonte, UFMG/CEDEPLAR, 1991, p.295-307.

Mortalidade infantil da população negra brasileira 1960-1980. Notas preliminares. Campinas, NEPO/UNICAMP, 1987. (Textos NEPO, 11) p. 104-128.

TELLES, E. E. Contato racial no Brasil urbano: análise da segregac,ão racial nas quarenta maiores áreas urbanas do Brasil em 1980. In: LOVELL, P. A. org. Desigualdade racial no Brasil contemporâneo. Belo Horizonte, UFMG/CEDEPLAR, 1991. p. 341 -65.

VETTER, D. M.; MASSENA, R. M. R. Quem se apropria dos beneficias líquidos dos investimentos do Estado em infra-estrutura urbana? In: SILVA, L. A. M. org. Solo urbano. Tópicos sobre o uso da terra. Rio de laneiro, Zahar, 1982 (Debates urbanos) p. 40-77.

VERTER, D. M.; SIMÕES, C. C. S. Acesso à infraestrutura de saneamento básico e mortalidade. Boletim Demográfico. Rio de Janeiro, 10(4): 629, 1980. 


\section{TABELA 1}

Distribuição de domicílios particulares situados em zona urbana e rural em condições adequadas de saneamento por regiões - 1987

\begin{tabular}{lrc}
\hline REGIÕES & $\begin{array}{r}\text { DOMIĆLIOS PARTICULARES EM CONDIÇÕES } \\
\text { ADEQUADAS DE SANEAMENTO }\end{array}$ \\
\hline & TOTAL & $\%$ \\
\hline $\mathrm{N}^{*}$ & 376.623 & 2,3 \\
\hline $\mathrm{NE}$ & 1.640 .594 & 10,1 \\
\hline $\mathrm{CO}$ & 581.513 & 3,6 \\
\hline $\mathrm{SE}$ & 10.909 .253 & 67,3 \\
\hline $\mathrm{S}$ & 2.695 .734 & 16,6 \\
\hline BRASIL* & 16.203 .717 & 100,0 \\
\hline
\end{tabular}

Fonte: PNAD 87

* Excluida a zona rural da região Norte.

\section{TABELA 2}

Porcentagem de domicílios particulares em condições adequadas de saneamento por regiões - 1987

\begin{tabular}{l|c|c|c}
\hline REGIÕES & TOTAL & URBANO & RURAL \\
\hline $\mathrm{N}^{*}$ & - & 42,8 & - \\
\hline $\mathrm{NE}$ & 19,3 & 31,5 & 2,7 \\
\hline $\mathrm{CO}$ & 26,3 & 34,3 & 3,6 \\
\hline $\mathrm{SE}$ & 71,4 & 80,1 & 13,3 \\
\hline $\mathrm{S}$ & 51,0 & 64,4 & 21,1 \\
\hline BRASIL* & 50,4 & 63,5 & 9,3 \\
\hline
\end{tabular}

Fonte: Tabulações especiais da PNAD 87

* Excluída a zona rural da região norte.

\section{TABELA 3}

Moradores em domicílios particulares permanentes por cor segundo as regiões - 1987

\begin{tabular}{|c|c|c|c|c|c|c|c|c|}
\hline \multirow[t]{2}{*}{ REGIÕES } & \multicolumn{4}{|c|}{ TOTAL } & \multicolumn{4}{|c|}{ URBANO } \\
\hline & $\mathrm{B}$ & $\mathrm{PR}$ & $\mathrm{PA}$ & $\mathrm{N}$ & $\mathrm{B}$ & $\mathrm{PR}$ & PA & $\mathrm{N}$ \\
\hline $\mathrm{N}^{*}$ & 1,5 & 0,8 & 6,2 & 5,5 & 2,0 & 1,1 & 9,5 & 8,3 \\
\hline $\mathrm{NE}$ & 17,1 & 32,3 & 47,9 & 45,9 & 14,0 & 25,9 & 37,4 & 35,7 \\
\hline $\mathrm{CO}$ & 6,0 & 4,1 & 8,8 & 8,2 & 5,9 & 3,6 & 9,2 & 8,4 \\
\hline SE & 52,4 & 53,8 & 31,4 & 34,3 & 58,5 & 59,8 & 38,7 & 41,7 \\
\hline $\mathrm{S}$ & 22,9 & 9,0 & 5,6 & 6,1 & 19,6 & 9,6 & 5,2 & 5,8 \\
\hline
\end{tabular}

Fonte: PNAD 1987.

* Excluída a zona rural da região norte. 


\section{TABELA 4}

Crianças de 0 a 6 anos de zona urbana residindo em domicilios particulares com adequadas condições de saneamento por raça, rendimento mensal domiciliar per capita e regiões - 1987

\begin{tabular}{|c|c|c|c|c|c|c|c|c|c|c|c|c|c|c|c|c|c|c|}
\hline \multirow{2}{*}{$\begin{array}{l}\text { RENDIMENTO } \\
\text { (SM) }\end{array}$} & \multicolumn{3}{|l|}{$\mathrm{N}$} & \multicolumn{3}{|l|}{ NE } & \multicolumn{3}{|l|}{$\mathrm{CO}$} & \multicolumn{3}{|l|}{ SE } & \multicolumn{3}{|l|}{$\mathrm{S}$} & \multicolumn{3}{|c|}{ BRASIL } \\
\hline & $\mathrm{B}$ & $\mathrm{N}$ & $T$ & $\mathrm{~B}$ & $\mathrm{~N}$ & $\mathrm{~T}$ & $\mathrm{~B}$ & $\mathrm{~N}$ & $T$ & $\mathrm{~B}$ & $\mathrm{~N}$ & $\mathrm{~T}$ & $\mathrm{~B}$ & $\mathrm{~N}$ & $\mathrm{~T}$ & B & $\mathrm{N}$ & $\mathrm{T}$ \\
\hline Até $1 / 4$ & 11,5 & 5,0 & 6,2 & 9,8 & 7,9 & 8,4 & 11,0 & 5,5 & 7,2 & 44,6 & 27,7 & 34,8 & 22,5 & 18,0 & 18,2 & 21,1 & 12,2 & 15,2 \\
\hline+ de $1 / 4$ a $1 / 2$ & 17,4 & 14,4 & 14,9 & 16,8 & 17,3 & 17,0 & 13,0 & 15,4 & 14,5 & 51,9 & 38,0 & 44,9 & 31,0 & 19.8 & 29,1 & 34,0 & 24.3 & 28.5 \\
\hline+ de $1 / 2$ a 1 & 38,1 & 24,1 & 27,4 & 31,4 & 29,1 & 30,1 & 22.3 & 22,1 & 22,4 & 74,5 & 56.8 & 67,6 & 53,2 & 45,2 & 53,6 & 59.3 & 41,8 & 51,8 \\
\hline+ de 1 a 2 & 57,7 & 41,4 & 46,9 & 51,4 & 43,0 & 46,9 & 38,4 & 34,1 & 36,7 & 84,8 & 75,1 & 82,2 & 71,8 & 61,2 & 70,5 & 75.6 & 59.8 & 70,7 \\
\hline$+\operatorname{de} 2$ & 77,4 & 67,8 & 72,3 & 72,7 & 72,0 & 72,5 & 60,0 & 52,4 & 58,3 & 95.0 & 91,3 & 94,6 & 87,3 & 74,1 & 85.4 & 88,0 & 76,5 & 86.2 \\
\hline TOTAL. & 47,0 & 27,2 & 32.7 & 32,6 & 22,5 & 26,5 & 35,8 & 24.7 & 30,9 & 80,0 & 56,1 & 72.4 & 62,4 & 39.0 & 58.4 & 64.8 & 37.1 & 53.7 \\
\hline
\end{tabular}

Fonte: Tabulações especiais da PNAD 87.

\section{TABELA 5}

Porcentagem de crianças de 0 a 6 anos residindo em domicilios particulares permanentes com adequadas condiçôes de saneamento por cor, rendimento mensal domiciliar per capita segundo as regiōes - 1987

\begin{tabular}{|c|c|c|c|c|c|c|c|c|c|c|c|c|}
\hline \multirow{2}{*}{$\begin{array}{l}\text { RENDIMENTO } \\
(\mathrm{SM})\end{array}$} & \multicolumn{2}{|l|}{$\mathrm{N}$} & \multicolumn{2}{|l|}{$\mathrm{NE}$} & \multicolumn{2}{|l|}{$\mathrm{CO}$} & \multicolumn{2}{|l|}{ SE } & \multicolumn{2}{|l|}{ S } & \multicolumn{2}{|c|}{ BRASIL } \\
\hline & PR & PA & PR & $\mathrm{PA}$ & PR & $\mathrm{PA}$ & PR & PA & PR & PA & $\mathrm{PR}$ & PA \\
\hline Até $1 / 4$ & 0,0 & 5,1 & 7,2 & 8,0 & 0,0 & 5,8 & 35,0 & 26,0 & 14,7 & 21,5 & 17.0 & 11,6 \\
\hline$+1 / 4$ a $1 / 2$ & 11,9 & 14,4 & 21,2 & 16,9 & 27,9 & 14,5 & 37,1 & 38,3 & 26,7 & 21,4 & 30,7 & 23,3 \\
\hline$+1 / 2$ a 1 & 46,8 & 24,0 & 23,5 & 29,5 & 18,1 & 22,3 & 56,7 & 56,9 & 62,1 & 46,0 & 50,3 & 40,6 \\
\hline+1 a 2 & 7,9 & 42,1 & 38,3 & 43,3 & 19,3 & 34,7 & 81,6 & 74,0 & 81,1 & 58,9 & 73,4 & 58,2 \\
\hline+2 & 20,1 & 68,3 & 89,5 & 71,1 & 100,0 & 51,2 & 95,0 & 91,0 & 90,3 & 66,7 & 90,9 & 75,6 \\
\hline TOTAL & 15,9 & 27,4 & 19,6 & 22,8 & 25,5 & 24,7 & 54,0 & 56,6 & 50,4 & 38,5 & 42,7 & 36,4 \\
\hline
\end{tabular}

Fonte: Tabulações especiais da PNAD 87.

\section{TABELA 6}

Porcentagem de chefes de zona urbana residentes em domicilios com adequada condição de saneamento por raça, rendimento mensal domiciliar per capita segundo as regiôes - 1987

\begin{tabular}{|c|c|c|c|c|c|c|c|c|c|c|c|c|c|c|c|c|c|c|}
\hline \multirow{2}{*}{$\begin{array}{l}\text { RENI)IMENTO } \\
(\mathrm{SM})\end{array}$} & \multicolumn{3}{|c|}{$\mathrm{N}(42,8)^{*}$} & \multicolumn{3}{|c|}{$\operatorname{NE}(31,5)^{*}$} & \multicolumn{3}{|c|}{$\mathrm{CO}(34,3)^{*}$} & \multicolumn{3}{|c|}{$\operatorname{SE}(80,1)^{*}$} & \multicolumn{3}{|c|}{$\mathrm{S}(64,4)^{*}$} & \multicolumn{3}{|c|}{ BRASIL $(63,5)^{*}$} \\
\hline & B & $\mathrm{N}$ & $\mathrm{T}$ & B & $\mathrm{N}$ & $\mathrm{T}$ & $B$ & $\mathrm{~N}$ & $\mathrm{~T}$ & $\mathrm{~B}$ & $\mathrm{~N}$ & $\mathrm{~T}$ & $\mathrm{~B}$ & $\mathrm{~N}$ & $\mathrm{~T}$ & B & $\mathrm{N}$ & $\mathrm{T}$ \\
\hline Até $1 / 4$ & 16.4 & 9,5 & 10.8 & 10.6 & 8.7 & 3.4 & 9.7 & 7.9 & 4,4 & 51.8 & 30.5 & 21.9 & 26.3 & 17.3 & 10.7 & 26.7 & 14.1 & 8.1 \\
\hline$+\operatorname{de} 1 / 4$ a $1 / 2$ & 27,4 & 17.5 & 19,3 & 19,2 & 15.4 & 8.9 & 14.3 & 12.9 & 8.9 & 61.0 & 42.5 & 38.2 & 32.7 & 21.9 & 20.4 & 40.4 & 24.5 & 20.2 \\
\hline$+\mathrm{de} 1 / 2 \mathrm{a} 1$ & 41.4 & 28.9 & 31.5 & 31.0 & 26,3 & 20.4 & 22.3 & 20.3 & 16.2 & 75,8 & 58.5 & 59.3 & 54.5 & 40,1 & 41,0 & 60.2 & 41.5 & 41.9 \\
\hline+ de 1 a 2 & 62.7 & 43.0 & 48.5 & 48.5 & 40.2 & 37,1 & 37.2 & 32.1 & 29.7 & 87.1 & 74.8 & 78.6 & 69.8 & 55,9 & 60.1 & 77.1 & 59.9 & 64.9 \\
\hline+ de 2 & 80.5 & 66.3 & 72.2 & 73.5 & 67.2 & 66,3 & 58.1 & 52.4 & 50.8 & 95.3 & 85.4 & 91.6 & 86.8 & 72.7 & 81.9 & 89.9 & 75.0 & 83.9 \\
\hline TOTAl. & 58.9 & 36.6 & 42.8 & 39.3 & 26.6 & 19.3 & 39.5 & 28.5 & 26.3 & 86.3 & 64.8 & 71.4 & 68.3 & 42.7 & 51.0 & 73.8 & 45.4 & 50.4 \\
\hline
\end{tabular}

Fonte: Tabulações especiais da PNAD 87.

* \% de domicilios urbanos adequados no conjunto de domicilios urbanos da região. 


\section{TABELA 7}

Porcentagem de chefes de zona urbana em domicilios com adequada condição de saneamento por raça, sexo, rendimento mensal domiciliar per capita segundo as regiões - 1987

\begin{tabular}{|c|c|c|c|c|c|c|c|c|c|c|c|c|}
\hline \multirow{3}{*}{$\begin{array}{l}\text { RENDIMENTO } \\
\text { (SM) }\end{array}$} & \multicolumn{4}{|l|}{$\mathrm{N}$} & \multicolumn{4}{|l|}{$\mathrm{NE}$} & \multicolumn{4}{|l|}{$\mathrm{CO}$} \\
\hline & \multicolumn{2}{|l|}{$\mathrm{B}$} & \multicolumn{2}{|l|}{$\mathrm{N}$} & \multicolumn{2}{|l|}{$\mathrm{B}$} & \multicolumn{2}{|l|}{$\mathrm{N}$} & \multicolumn{2}{|l|}{ B } & \multicolumn{2}{|l|}{$\mathrm{N}$} \\
\hline & $\mathrm{H}$ & $\mathrm{M}$ & $\mathrm{H}$ & $M$ & $\mathrm{H}$ & $M$ & $\mathrm{H}$ & $M$ & $\mathrm{H}$ & M & $\mathrm{H}$ & $M$ \\
\hline Até $1 / 4$ & 16,0 & 17,8 & 9,7 & 8,9 & 10,1 & 11,7 & 8,5 & 9,3 & 6,5 & 16,8 & 5,8 & 12,5 \\
\hline+ de $1 / 4$ a $1 / 2$ & 25,7 & 34,1 & 16,1 & 22,1 & 17,1 & 24,3 & 15,6 & 14,7 & 14,4 & 14,0 & 13,7 & 11,1 \\
\hline+ de $1 / 2$ a 1 & 43,0 & 34,5 & 27,9 & 33,3 & 29,8 & 35,3 & 26,6 & 25,2 & 20,4 & 31,3 & 19,6 & 22,7 \\
\hline$+\operatorname{de} 1$ a 2 & 60,8 & 70,6 & 43,1 & 42,1 & 47,7 & 51,4 & 40,2 & 40,0 & 34,9 & 47,3 & 30,4 & 40,1 \\
\hline$+\operatorname{de} 2$ & 80,3 & 81,5 & 65,2 & 74,6 & 72,5 & 78,7 & 66,0 & 75,2 & 55,9 & 70,3 & 48,8 & 71,0 \\
\hline TOTAL & 59,2 & 57,5 & 36,8 & 35,5 & 39,5 & 38,4 & 27,4 & 23,9 & 38,1 & 46,1 & 27,7 & 31,5 \\
\hline
\end{tabular}

\begin{tabular}{|c|c|c|c|c|c|c|c|c|c|c|c|c|}
\hline \multirow{3}{*}{$\begin{array}{l}\text { RENDIMENTO } \\
\text { (SM) }\end{array}$} & \multicolumn{4}{|l|}{$\mathrm{SE}$} & \multicolumn{4}{|l|}{$\mathrm{S}$} & \multicolumn{4}{|c|}{ BRASIL } \\
\hline & \multicolumn{2}{|l|}{$\mathrm{B}$} & \multicolumn{2}{|l|}{$\mathrm{N}$} & \multicolumn{2}{|l|}{ B } & \multicolumn{2}{|l|}{$\mathrm{N}$} & \multicolumn{2}{|c|}{$\mathrm{B}$} & \multicolumn{2}{|l|}{$\mathrm{N}$} \\
\hline & $\mathrm{H}$ & $\mathrm{M}$ & $\mathrm{H}$ & M & $\mathrm{H}$ & $\mathrm{M}$ & $\mathrm{H}$ & $M$ & $\mathrm{H}$ & M & $\mathrm{H}$ & $\mathrm{M}$ \\
\hline Até $1 / 4$ & 55,3 & 42,2 & 33,0 & 24,6 & 26,5 & 25,8 & 11,9 & 34,4 & 28,0 & 23,5 & 14,1 & 14,4 \\
\hline$+\operatorname{de} 1 / 4$ a $1 / 2$ & 60,4 & 62,7 & 41,5 & 45,3 & 30,6 & 41,7 & 21,8 & 22,1 & 39,1 & 44,3 & 24,2 & 25,7 \\
\hline+ de $1 / 2$ a 1 & 74,5 & 80,9 & 59,0 & 56,4 & 55,2 & 51,7 & 45,1 & 23,8 & 59,5 & 63,3 & 42,0 & 39,8 \\
\hline+ de 1 a 2 & 86,7 & 89,3 & 74,4 & 76,6 & 68,8 & 75,1 & 56,7 & 50,4 & 76,5 & 79,9 & 59,5 & 62,0 \\
\hline$+\operatorname{de} 2$ & 95,1 & 96,3 & 84,8 & 88,1 & 86,1 & 91,1 & 73,0 & 70,8 & 89,3 & 92,6 & 73,8 & 81,7 \\
\hline TOTAL & 86,3 & 86,7 & 65,5 . & 62,3 & 68,3 & 68,3 & 44,8 & 34,2 & 73,9 & 73,3 & 46,0 & 42,9 \\
\hline
\end{tabular}

Fonte: Tabulações especiais da PNAD 87.

\section{TABELA 8}

Porcentagem de chefes residentes em domicilios com adequada condição de saneamento por cor, rendimento mensal domiciliar per capita segundo as regiões - 1987.

\begin{tabular}{|c|c|c|c|c|c|c|c|c|c|c|c|c|}
\hline \multirow{2}{*}{$\begin{array}{l}\text { RENDIMENTO } \\
\text { (SM) }\end{array}$} & \multicolumn{2}{|l|}{$\mathrm{N}$} & \multicolumn{2}{|l|}{ NE } & \multicolumn{2}{|l|}{$\mathrm{CO}$} & \multicolumn{2}{|l|}{ SE } & \multicolumn{2}{|l|}{$\mathrm{S}$} & \multicolumn{2}{|c|}{ BRASIL } \\
\hline & PR & PA & PR & PA & PR & PA & PR & PA & PR & PA & PR & PA \\
\hline Até $1 / 4$ & 0,0 & 9,7 & 6,7 & 8,7 & 0,0 & 8,7 & 35,6 & 28,6 & 15,4 & 17,7 & 17,7 & 13,4 \\
\hline+ de $1 / 4$ a $1 / 2$ & 12,5 & 17,6 & 13,8 & 15,4 & 18,0 & 12,3 & 40,5 & 43,2 & 26,5 & 20,5 & 28,6 & 23,7 \\
\hline + de $1 / 2$ a 1 & 18,9 & 29,2 & 24,0 & 26,3 & 16,5 & 20,6 & 54,5 & 59,8 & 48,3 & 37,4 & 45,2 & 40,8 \\
\hline+ de 1 a 2 & 16,3 & 43,8 & 39,5 & 40,2 & 36,0 & 31,8 & 73,3 & 75,8 & 56,3 & 55,7 & 64,7 & 59,0 \\
\hline+ de 2 & 48,2 & 66,7 & 55,1 & 68,1 & 69,4 & 51,4 & 79,9 & 86,5 & 79,7 & 69,7 & 75,8 & 74,9 \\
\hline TOTAL & 20,6 & 37,0 & 21,1 & 27,4 & 29,0 & 28,4 & 59,7 & 66,3 & 49,6 & 40,4 & 47,4 & 45,0 \\
\hline
\end{tabular}

Fonte: Tabulações especiais da PNAD 87. 


\section{TABELA 9}

Porcentagem de chefes residentes em domicilios com adequada condição de saneamento por cor, sexo, rendimento mensal domiciliar per capita segundo as regiões - 1987.

\begin{tabular}{|c|c|c|c|c|c|c|c|c|c|c|c|c|}
\hline \multirow{3}{*}{$\begin{array}{l}\text { RENDIMENTO } \\
\text { (SM) }\end{array}$} & \multicolumn{4}{|l|}{$\mathrm{N}$} & \multicolumn{4}{|l|}{$\mathrm{NE}$} & \multicolumn{4}{|l|}{$\mathrm{CO}$} \\
\hline & \multicolumn{2}{|l|}{$\mathrm{H}$} & \multicolumn{2}{|l|}{ M } & \multicolumn{2}{|l|}{$\mathrm{H}$} & \multicolumn{2}{|l|}{$\mathrm{M}$} & \multicolumn{2}{|l|}{$\mathrm{H}$} & \multicolumn{2}{|l|}{$\mathrm{M}$} \\
\hline & PR & PA & PR & PA & PR & PA & PR & PA & PR & PA & PR & PA \\
\hline Até $1 / 4$ & 0,0 & 10,0 & 0,0 & 9,0 & 5,9 & 28,0 & 8,1 & 9,6 & 0,0 & 6,3 & 0,0 & 13,7 \\
\hline+ de $1 / 4$ a $1 / 2$ & 5,0 & 16,4 & 35,8 & 21,7 & 15,5 & 8,9 & 10,1 & 15,6 & 19,9 & 12,9 & 12,9 & 10,8 \\
\hline + de $1 / 2$ a 1 & 17,0 & 28,2 & 23,1 & 34,0 & 24,4 & 15,7 & 23,3 & 25,6 & 12,5 & 20,2 & 31,5 & 21,9 \\
\hline$+\operatorname{de} 1$ a 2 & 17,6 & 44,0 & 0,0 & 42,6 & 42,2 & 26,8 & 31,2 & 41,5 & 36,1 & 30,0 & 35,8 & 40,6 \\
\hline+ de 2 & 40,3 & 65,7 & 75,0 & 74,6 & 53,4 & 40,0 & 60,9 & 77,0 & 65,4 & 47,9 & 85,7 & 69,9 \\
\hline TOTAL & 17,5 & 37,3 & 31,8 & 35,6 & 22,5 & 66,8 & 17,8 & 25,1 & 28,1 & 27,7 & 32,1 & 31,4 \\
\hline
\end{tabular}

\begin{tabular}{|c|c|c|c|c|c|c|c|c|}
\hline \multirow{3}{*}{$\begin{array}{c}\text { RENDIMENTO } \\
\text { (SM) }\end{array}$} & \multicolumn{4}{|l|}{ SE } & \multicolumn{4}{|l|}{$\mathrm{S}$} \\
\hline & \multicolumn{2}{|l|}{$\mathrm{H}$} & \multicolumn{2}{|l|}{ M } & \multicolumn{2}{|l|}{$\mathrm{H}$} & \multicolumn{2}{|l|}{$\mathrm{M}$} \\
\hline & PR & PA & PR & PA & PR & PA & PR & PA \\
\hline Até $1 / 4$ & 34,9 & 32,3 & 18,1 & 24,6 & 0,0 & 14,4 & 44,5 & 30,3 \\
\hline de & 38,8 & 42,4 & 45,9 & 45,3 & 29,0 & 20,0 & 20,0 & 23,0 \\
\hline$+\operatorname{de} 1 / 2$ a & 55,8 & 60,0 & 58,7 & 56,4 & 55,4 & 41,7 & 25,7 & 23,1 \\
\hline+ de 1 a 2 & 71,2 & 75,2 & 75,5 & 76,6 & 57,9 & 56,2 & 45,9 & 52,2 \\
\hline$+\operatorname{de} 2$ & 77,3 & 86,2 & 87,9 & 88,1 & 80,5 & 69,9 & 75,4 & 68,8 \\
\hline TOTAL & 59,6 & 67,1 & 63,2 & 62,3 & 53,0 & 42,1 & 37,1 & 33,0 \\
\hline
\end{tabular}

Fonte: Tabulações especiais da PNAD 87. 